\title{
QUAY DESIGN AND OPERATIONAL OCEANOGRAPHY. THE CASE OF BILBAO HARBOUR
}

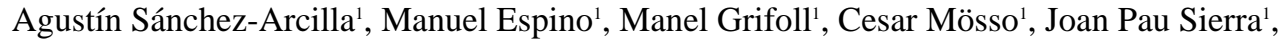 \\ Marc Mestres $^{1}$, Stella Spyroupoulu ${ }^{1}$, Mario Hernáez², Alberto Ojanguren² ${ }^{2}$, Marcos G.-Sotillo ${ }^{3}$ \\ and Enrique Alvarez-Fanjul ${ }^{3}$
}

\begin{abstract}
In this paper a harbour engineering application of an operational system to forecast circulation and transport fields is presented. It deals with the functional design of a quay in the Bilbao harbour (Bay of Biscay, North-Atlantic coast of Spain). The aim is to use physical oceanography "tools" to design the optimal quay alignment according to two criteria: i) Minimize the currents in order to guarantee the vessel maneuverability and quay operability for given safety levels and ii) Maximize the water renewal capacity of the harbour inner basins (beyond the studied quay) in order to reduce the risk of water quality degradation. The methodology and the results reveal a new procedure to enhance the harbour lay-out design from an environment point of view.
\end{abstract}

Keywords: quay design; operational oceanography; hydrodynamic modeling; residence time; environmental design

\section{INTRODUCTION}

Numerical models have been used historically as a tool for harbour design. The modelling suites started, historically, with wave propagation models, first deterministic and next for a wave spectum. This was followed by wave generation codes and, lately, by circulation and transport models. The wave simulations provide information on wave conditions inside a harbour area which is essential for the structural design during the project design (Oliver et el., 1996) and for the future operative conditions (González-Marco et al., 2006). Environmental design aspects have gained progresive importance in recent years. Improving harbour water quality is an objective of vital importance for the sustainable development of harbour and nearby coastal waters. Recently, Benfer et al. (2010), have used a numerical model and water renewal parameterization in order to optimize the channels systems of a marina. Stamou et al., (2004) have applied a hydrodynamic numerical model in order to assess the improvement of water renewal due to the construction of a flushing channel in a small harbour. For more offshore areas, Kantardgi et al., (1995) evaluate through analytical and simplified numerical methods the water exchange in a coastal area with submerged structures. Nevertheless, environmental design based on numerical modeling is not yet systematically taken into account during the design phase of the projects. Moreover the forecasting capabilities for wave and current fields are seldom considered jointly in harbour exploitation plans. To contribute to a more process-based design and exploitation for harbour structures in this paper we present an example of an environmental design for a new quay in the Bilbao harbour. The aim is to evaluate numerically the water renewal differences in three quay-designs and determine the best solution. The hydrodynamic drivers have been obtained from the operational oceanography system currently implemented at the Bilbao harbour. The conclusions underline the influence of quay-shape on water renewal of inner basins.

\section{METHODOLGHY}

\section{Bilbao harbour and hydrodynamic model}

Bilbao harbour is located in the Bay of Biscay, North-Atlantic coast of Spain (see Figure 1). The hydrodynamic behaviour of this harbour has been already studied by Grifoll et al. (2009) using numerical modelling, where a collection of numerical experiments was designed to assess the hydrodynamic forcing-response mechanism. The model was calibrated in terms of bottom drag coefficient. The numerical results agreed well with current velocity data and sea level variation. The results by Grifoll et al. (2009) indentified a noticeable influence of tidal wave propagation on the current field. This influence was estimated between $60 \%$ and $90 \%$ as a function of the wind regime, and lower in the innermost part of the estuary, due to the freshwater discharge from the Nervión River.

\footnotetext{
${ }^{1}$ Laboratori d'Enginyeria Marítima (LIM), Technical University of Catalonia (UPC), Barcelona, Spain.

2 Bilbao Harbour Authority, Bilbao, Spain.

${ }^{3}$ Puertos del Estado (Spanish Harbour Agency), Madrid, Spain.
} 
In addition, the influence of the tidally-driven flow on the currents increased with depth due to the role played by the wind.

In the present contribution, the same implementation of ROMS than that presented by Grifoll et al. (2009) has been used. The implementation of ROMS at Bilbao harbour consists of a structured, equally-spaced mesh of 218 grid points in the alongshore direction and 176 grid points in the crossshore direction with a mean grid resolution of 38 meters. Five sigma (terrain following) layers were used to discretize the vertical direction.

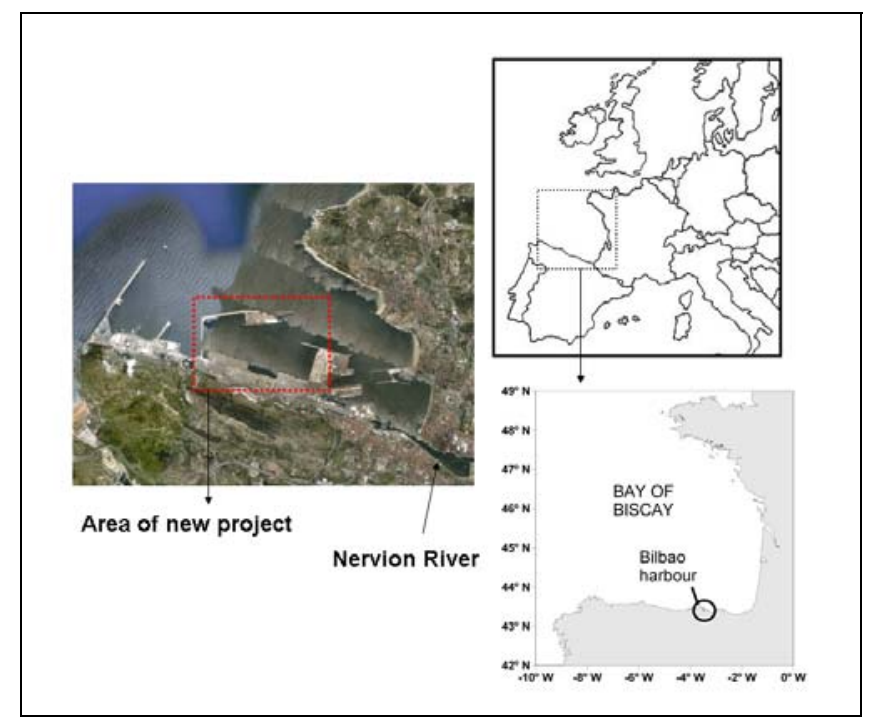

Figure 1. Bilbao harbour location in the North Atlantic

(Cantabric) coast of Spain. The Nervión River and the area of the new quay project are also shown (in dashed line).

\section{Operational oceanography system}

Operational oceanographic systems for harbours have until now focused on measuring and forecasting useful parameters for the management of harbour activities such as waves (GonzálezMarco et al., 2008) and sea level (Álvarez-Fanjul et al., 2001). However, the implementation of similar systems oriented to characterize and forecast harbour circulation in real-time is not so widespread. The lack of such operational circulation systems becomes a significant limitation in terms of assessing the risks associated to water quality degradation or pollutant spillages. In that sense, the Spanish Harbour organization Puertos del Estado is currently making significant efforts to provide on-line the most complete knowledge on the prevailing environmental conditions within the harbour and nearby areas. As an example, the operational scheme for Bilbao harbour is shown in Figure 2. On the first level, there is the ESEOAT model which covers the area of the Bay of Biscay with a $5 \mathrm{~km}$ resolution. On the second level, the ROMS model is implemented in the shelf-slope area of the northern Spanish coasts with a spatial resolution of $200 \mathrm{~m}$. This model (called COASTAL model) is nested into the ESEOAT model. On all levels, the atmospheric forcing is obtained from the AEMET products. Initial conditions for the harbour model are taken from the shelf model but a routine campaign program is planned to be launched in the near future for obtaining weekly CTD measurements inside and outside the harbour domain. The system is run operationally every day by Puertos del Estado. The model starts at $\left(\mathrm{t}_{0}-72 \mathrm{~h}\right)$ in hindcast mode using analysed fields of atmospheric and oceanic variables. Then, from $\mathrm{t}_{0}$ to $\left(\mathrm{t}_{0}+72 \mathrm{~h}\right)$ the model runs in forecast mode, forced by the corresponding atmospheric and oceanic forecasts. 


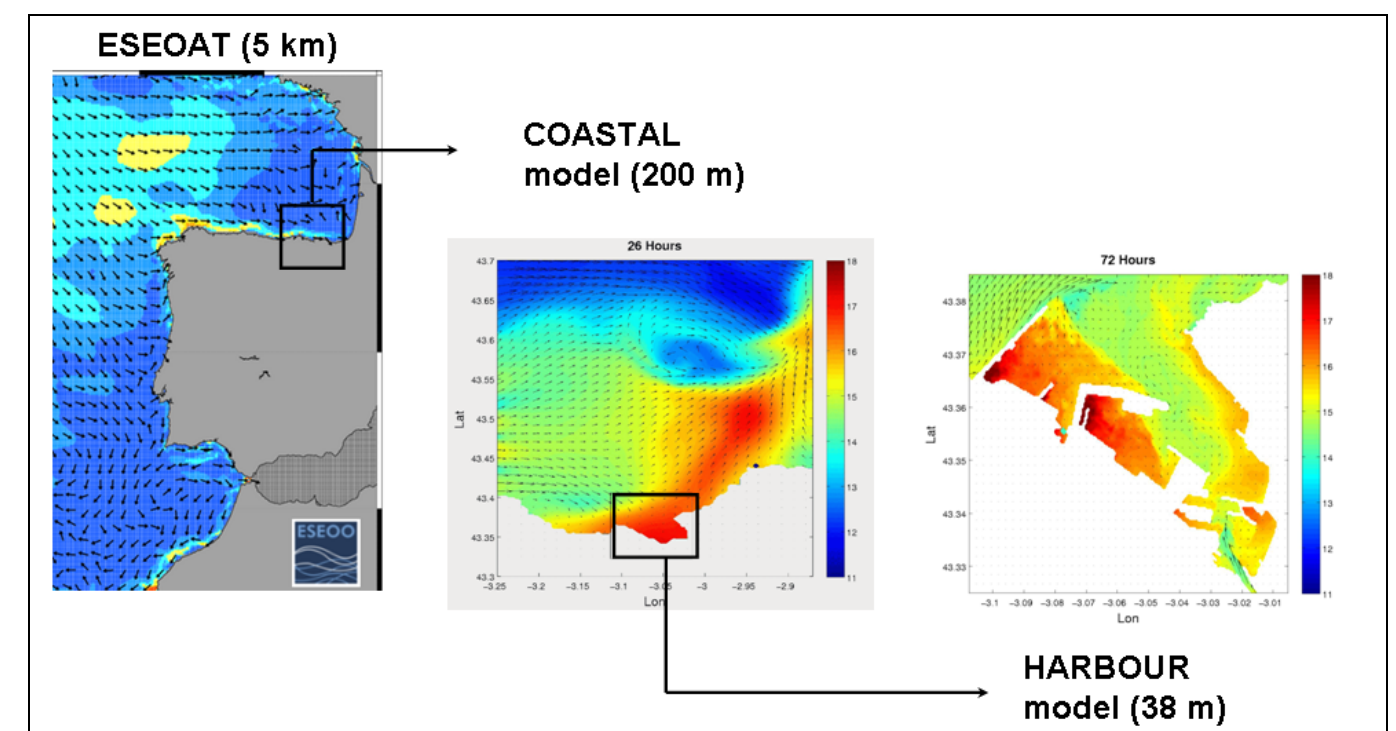

Figure 2. Numerical domains and snapshots of the nested hydrodynamic models for harbour and coastal models and the velocity module for regional model ESEOAT. The figures showing the temperature field also show the plot for the velocity field.

\section{Water renewal parameterization}

In this study the definition of Local Flushing Time (LFT) by Plus et al. (2009) was used. The methodology applied to compute the LFT is based on the numerical deployment of an Eulerian conservative tracer in the inner domain of the harbour and computes the time required in each water parcel for the tracer concentration to fall below $37 \%$ (i.e. $\mathrm{e}^{-1}$ ) of the initial concentration. This definition coincides with the concept of Eulerian Water Transport Time (Cucco et al., 2009), Local Residence Time (Abdelrhman, 2005) and represents the sum of Flushing Lag and Local e-Flusing Time in Jouon et al. (2006).

In order to compute the vertical variability of water renewal, an Eulerian passive tracer with a concentration equal to 1 was deployed in the different sigma layers of the computational domain. From here the spatial distributions of LFT at different depths were obtained, focusing on the surface layer $(\mathrm{z}=-0.5 \mathrm{~m})$ and the deep layer $(\mathrm{z}=-9 \mathrm{~m})$. Complementary, an integral definition of water renewal was also computed for each depth by averaging the concentration in the cells of the domain and evaluating the time evolution curves. This integral description is the e-Flushing time and is defined as the time required for the tracer mass initially contained in the domain to be reduced by a factor $\mathrm{e}^{-1}$ (Jouon et al., 2006). This parameter was named Integral Flushing Time (IFT) by Plus et al., (2009) or Flushing Time by Abdelrhman (2002).

\section{Quay design}

According to the Bilbao port development plan, a new quay will be built in the Zierbena harbour. We are considering three different designs, A, B and C (see Figure 3) which provide the same land area and similar berthing lengths. Starting from the results of the COASTAL model, three different grids with the three quay designs have been nested following the scheme of figure 2. 


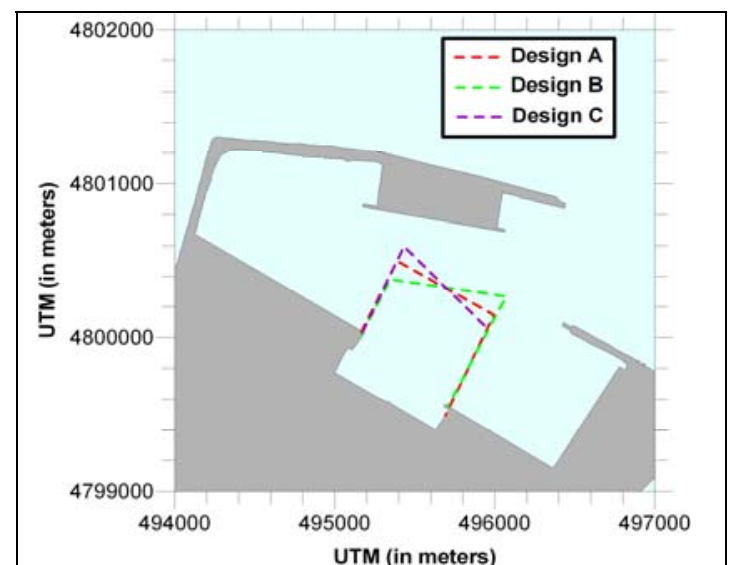

Figure 3. Possible new quay lay-outs for the new Bilbo harbour, corresponding to the dashed square in Figure 1.

\section{RESULTS}

The operational system has been run for the three quay designs during 25 days in order to obtain the time-varying and averaged water currents. Next the methodologies previously described to parameterize the water renewal have been applied. The LFT's are shown in Figure 4. The plots reveal common features, such as the lowest water renewal rates (largest LFT) obtained in the west zone of the basin and reaching up to 250 hours. In a general, the largest water renewal is obtained for design $\mathrm{B}$. The integral computation for water renewal has been also performed. The results of IFT for the three cases are: 157 hours for case A, 135 hours for case B and 220 hours for case C. These values confirm the expected behavior, according to Figure 3 geometry.

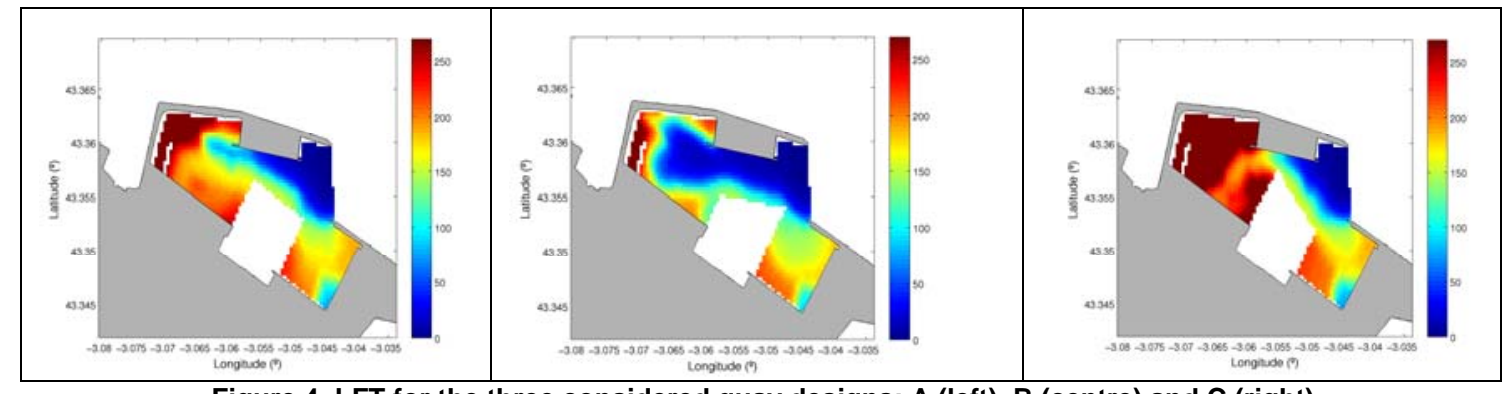

Figure 4. LFT for the three considered quay designs: A (left), B (centre) and C (right).

Additionally, the maximum velocities during the analysis period have been computed in the harbour domain for the three cases. The aim is to minimize the maximum velocities in order to guarantee the vessel maneuverability. In Figure 5 the maximum velocities for the three designs are shown. According to the results the velocities computed are below of the threshold of maximum velocities provided by the ROM 3.1 (1999) "Spanish recommendations of Maritime works: Design of Harbours and flotation areas” which is $0.7 \mathrm{~m} / \mathrm{s}$. Nevertheless, the higher maximum velocities happen for design B.

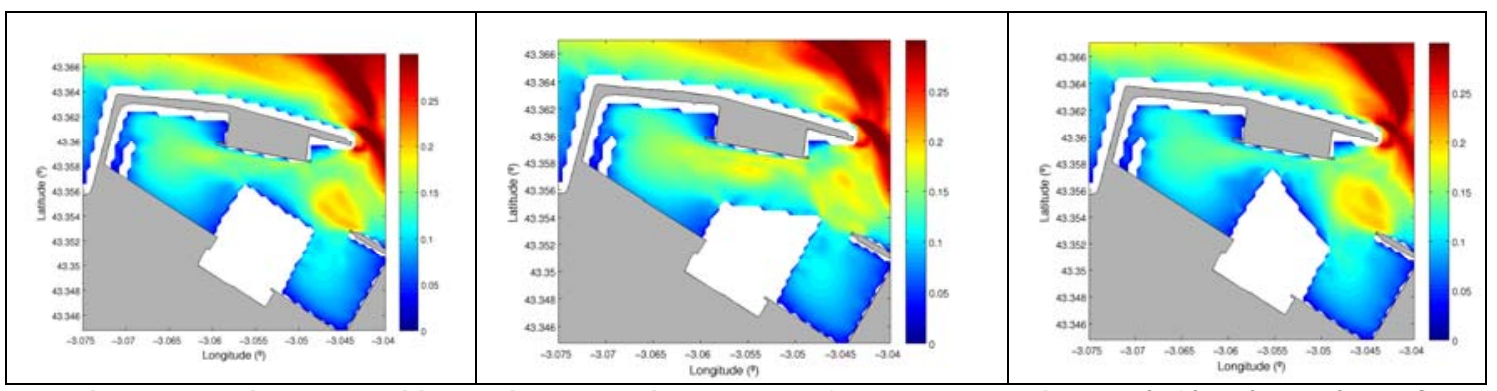

Figure 5. Maximum velocities during the period analysed for the three designs: A (left), B (centre) and C (right). 


\section{CONCLUSIONS}

This paper deals with the use of oceanographic models to provide an environmentally friendly harbour design and to give support to harbour lay-out decisions from a maneuverability standpoint. We have applied this approach to develop quay-designs within a harbour. The obtained hydrodynamic simulations (through operational oceanography system) have proved to be a powerful design tool. This means, that operational products can play an important role in design phase complementing their role in daily management of the harbour. The results have shown the optimum design in order to maximize water renewal while checking that the maximum velocities are still acceptable for ship maneuverability. Nevertheless, we suggest further analysis on water renewal including validation with field data in order to confirm this solution. The sensitivity of water renewal to the tidal range, the initial passive tracer deployment or the wind influence on water behavior should be analyzed in depth. Although the work has been done for the Bilbo harbour, the obtained results and methodology are of generic value and could be used for other habour domains.

\section{ACKNOWLEDGMENTS}

The authors want to acknowledge the European research project FIELD_AC (contract number 242284) within which this research has been partly developed.

\section{REFERENCES}

Abdelrhman, M.A. 2002. Modeling how a hurricane barrier in New Bedford Harbour, Massachusetts, affects the hydrodynamics and residence time. Estuaries, 25 (2), 177-196.

Abdelrhman, M.A. 2005. Simplified modelling of flushing and residence time in 42 embayments in New England, USA, with special attention to Greenwhich Bay, Rhode Island. Estuarine, Coastal and Shelf Science, 62, 339-351.

Álvarez-Fanjul, E., Pérez, B., Rodríguez, I., 2001. NIVMAR: a storm surge forecasting system for Spanish waters. Scientia Marina, 65, 145-154.

Benfer, N.P., King, B.A., Lemckert, C.J., Zigic, S. 2010. Modeling the Effect of Flow Structure Selection on Residence Time in an Artificial Canal System: Case Study. Journal of Waterway, Port, Coastal and Ocean Engineering, 136 (2), 91-96.

Cucco, A., Umgiesser, G., Ferrarin, C., Perelli, A., Canu, D.M., Solidoro, C., 2009. Eulerian and lagrangian transport time scales of a tidal active coastal basin. Ecological Modelling 220, 913922.

González-Marco, D., Sierra, J. P. Fernandez de Ybarra, Sánchez-Arcilla, A. 2008. Implications of long waves in harbor management. The Gijon Port case study. Ocean \& Coastal Management, 51 (2), 180-201.

Grifoll, M., Fontán, A., Ferrer, L., Mader, J., González, M., Espino, M. 2009. 3D hydrodynamic characterization of a meso-tidal harbour: The case of Bilbao harbour (northern Spain). Coastal Engineering, 56, 907-918.

Jouon, A., Douillet, P., Ouillon, S., Fraunié, P. 2006. Calculations of hydrodynamic time parameters in a semi-opened coastal zone using a 3D hydrodynamic model. Continental Shelf Research, 26, 1395-1415.

Kantardgi, I., Mairanovsky, F., Sapova, N. 1995. Water exchange and water quality in the coastal zone in the presence of structures. Coastal Engineering 26, 207-223.

Oliver, J., Plotkin, D., Lesnik, J., Pirie, D. 1996. Condition and Performance Rating System for Breakwaters and Jetties. Proceedings of $14^{\text {th }}$ International Conference on Coastal Engineering, ASCE, 1852-1861.

Plus, M., Dumas, F., Stanisière, J.-Y., Maurer, D. 2009. Hydrodynamic chractaerization of the Archachon Bay, using model-derived descriptors. Continental Shelf Research, 29, 1008-1013.

ROM 3.1., 1999. Spanish recommendations of Maritime works: Design of Harbours and flotation areas. Edited by Puertos del Estado (Spanish harbour autorithy).

Stamou, I., Katsiris, I.K., Moutzouris, C. I., Tsoukala, V.K. 2004. Improvement of marina design technology using hydrodynamic models. Global Nest: the Int. J. Vol 6, No 1, pp 63-72. 